\title{
Erectile dysfunction among Thai patients with COVID-19 infection
}

\author{
Kawintharat Harirugsakul ${ }^{1} \wedge$, Sorawit Wainipitapong ${ }^{2} \wedge$, Jeerath Phannajit ${ }^{3}$, Leilani Paitoonpong ${ }^{4}$, \\ Kavirach Tantiwongse ${ }^{1 \wedge}$
}

${ }^{1}$ Division of Urology, Department of Surgery, Faculty of Medicine, Chulalongkorn University and King Chulalongkorn Memorial Hospital, the Thai Red Cross Society, Bangkok, Thailand; ${ }^{2}$ Department of Psychiatry and Center of Excellence in Transgender Health (CETH), Faculty of Medicine, Chulalongkorn University and King Chulalongkorn Memorial Hospital, the Thai Red Cross Society, Bangkok, Thailand; ${ }^{3}$ Division of Clinical Epidemiology and Division of Nephrology, Department of Medicine, Faculty of Medicine, Chulalongkorn University and King Chulalongkorn Memorial Hospital, the Thai Red Cross Society, Bangkok, Thailand; ${ }^{4}$ Division of Infectious Diseases, Department of Medicine, Faculty of Medicine, Chulalongkorn University and King Chulalongkorn Memorial Hospital, the Thai Red Cross Society, Bangkok, Thailand

Contributions: (I) Conception and design: K Harirugsakul, S Wainipitapong, K Tantiwongse; (II) Administrative support: K Tantiwongse; (III) Provision of study materials or patients: L Paitoonpong; (IV) Collection and assembly of data: K Harirugsakul; (V) Data analysis and interpretation: K Harirugsakul, S Wainipitapong, J Phannajit; (VI) Manuscript writing: All authors; (VII) Final approval of manuscript: All authors.

Correspondence to: Kavirach Tantiwongse. Division of Urology, Department of Surgery, Faculty of Medicine, Chulalongkorn University and King Chulalongkorn Memorial Hospital, the Thai Red Cross Society, 1873, Rama IV Rd. Pathumwan, Bangkok, 10330, Thailand. Email: Kavirach@chula.md.

Background: Erectile dysfunction (ED) is suspected to be the symptom manifestation of COVID-19. However, scarce data was presented this day. Our study was conducted to determine the prevalence of ED and its associated factors among Thai patients with COVID-19.

Methods: Sexually active males with COVID-19, hospitalized between May and July 2021 at one university hospital in Bangkok, were screened for erectile dysfunction by the International Index of Erectile Function 5 (IIEF-5). Demographic data and COVID-19 treatment history were collected. Mental health status, including depression and anxiety, was evaluated with the Thai Patient Health Questionnaire 9 (PHQ-9) and the Generalized Anxiety Disorder Scale (GAD-7), respectively. The sample size was calculated, and logistic regression was used to analyze the association.

Results: One hundred fifty-three men with COVID-19 were recruited. ED prevalence was 64.7\%, of which severity was mostly mild. Logistic regression, adjusted for age, BMI, and medical comorbidities, portrayed a significant association between ED and mental health status. Higher risk of ED was found in participants with major depression [adjusted OR 8.45, 95\% CI: 1.01-70.96, P=0.049] and higher GAD-7 total score [adjusted OR 1.15, 95\% CI: 1.01-1.31, P=0.039].

Conclusions: Thai patients with COVID-19 had high prevalence of ED, which was associated with mental disorders. Thus, screening for mental problems is recommended in individuals with COVID-19 and ED.

Keywords: Anxiety; COVID-19; depression; erectile dysfunction (ED)

Submitted Sep 12, 2021. Accepted for publication Nov 10, 2021.

doi: $10.21037 / \mathrm{tau}-21-807$

View this article at: https://dx.doi.org/10.21037/tau-21-807

\footnotetext{
^ ORCID: Kawintharat Harirugsakul, 0000-0002-8332-1242; Sorawit Wainipitapong, 0000-0001-6306-0930; Kavirach Tantiwongse, 00000001-8557-924X.
} 


\section{Introduction}

The global COVID-19 pandemic, caused by the SARS$\mathrm{CoV}-2$ virus, has affected entire populations worldwide. Apart from the respiratory system, which is its main manifestation, extrapulmonary manifestations of COVID-19 infection could also be found, including symptoms of the reproductive system. The negative impact on male reproductive health should be of concern because the virus can directly injure testicular tissues by binding with angiotensin-converting enzyme 2 (ACE2) receptors highly expressed in the reproductive organs (1). The presence of virus in penile tissues, and relatively lower levels of endothelial progenitor cells were reported in two patients with a history of COVID-19 infection. They were subsequently diagnosed with severe erectile dysfunction (ED) which could be explained by endothelial dysfunction (2).

In patients with COVID-19, ED is caused by multiple physical and mental etiologies such as endothelial dysfunction, subclinical hypogonadism, pulmonary hemodynamic impairment, and mental comorbidities (3). Mental health problems are considered to be an obvious consequence of the pandemic. Higher rates of psychiatric disorders were globally reported during the outbreak, including major depression and anxiety disorders (4). These several contributing factors complicate the etiologies of $\mathrm{ED}$ in the pandemic among men in good health and male patients with either recovered or current COVID-19 infection.

Although patients with current COVID-19 infection should have the highest risks of developing ED, studies in this population are limited. Twenty-five COVID-19 positive patients were reported to have higher ED prevalence than seventy-five participants from the control group (5). Furthermore, population-specific studies are necessary for sexual dysfunction research because of region-specific cultural differences and conservative beliefs, especially in Asian countries, where sexual dysfunctions are usually undiagnosed and untreated (6).

To date, there is still no study evaluating ED and its contributing factors among patients with COVID-19 infection in Thailand. It is questionable whether ED in this Asian country would differ from previous studies in non-Asian populations. The aim of our study was to measure the prevalence of ED by using a Thai version of the International Index of Erectile Function 5 (IIEF-5) among patients with current COVID-19 infection. We also examined the correlation between ED and related factors, including age, BMI, mental health status and COVID-19 treatment during hospitalization.

We present the following article in accordance with the STROBE reporting checklist (available at https://dx.doi. org/10.21037/tau-21-807).

\section{Methods}

\section{Study population}

Between May and July 2021, all sexually active males, defined as self-reported having sexual intercourse in recent two weeks, patients aged between 18-70 years old who were hospitalized for COVID-19 infection at one university hospital in Bangkok, Thailand, were invited for assessment. Those with severe medical and mental illnesses were excluded. Prior to assessment, informed consent was obtained verbally or via an online application for prevention of viral transmission. Instead of online assessment questionnaires, phone interview was done with participants who were illiterate. The study was conducted in accordance with the Declaration of Helsinki (as revised in 2013). The study was approved by Chulalongkorn University's Institutional Review Board (IRB No. 408/2021) and informed consent was taken from all the participants.

Demographic data including age, BMI, underlying diseases, and history of alcohol and nicotine use were obtained. Details about COVID-19 vaccination and treatment during hospitalization were extracted. The sample size was calculated based on prior studies and required a total sample of seventy-eight (5).

\section{A Thai version of the International Index of Erectile Function 5 (IIEF-5)}

Erectile function was measured by a Thai version of IIEF-5. This tool has five questions focusing on ED and satisfaction of sexual intercourse. Its scores negatively correlated with ED severity and could be classified into five levels; severe [5-7], moderate [8-11], mild to moderate [12-16], mild [17-21], and no ED [22-25] (7).

\section{Mental bealth status}

\section{The Thai Patient Health Questionnaire 9 (PHQ-9)}

The PHQ-9 was used to evaluate depressive symptoms, including depressed mood, loss of interest and energy, sleep and appetite problems, feelings of worthlessness, trouble 


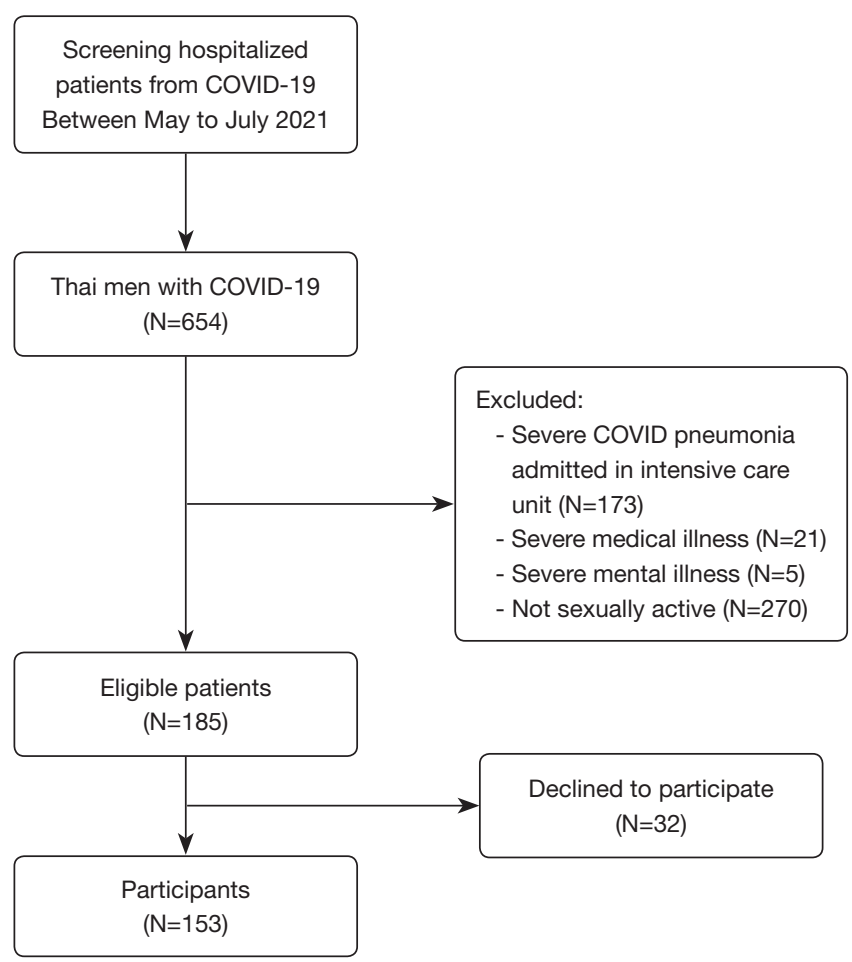

Figure 1 Study protocol.

concentrating, psychomotor abnormalities, and thoughts of death or self-injury. A PHQ-9 score of $\geq 9$ is considered positive for major depression, with sensitivity and specificity of 0.84 and 0.77 respectively (8).

\section{The Generalized Anxiety Disorder Scale (GAD-7)}

The GAD-7 scale is an assessment for generalized anxiety disorder and anxiety severity. The measured symptoms included nervousness, uncontrolled and excessive worrying, trouble relaxing, restlessness, irritability, and fear that something awful might happen. A GAD-7 score of $\geq 10$ represents a cut point for identifying generalized anxiety disorder with sensitivity and specificity of 0.89 and 0.82 , respectively (9).

\section{Statistical analysis}

Descriptive statistics were used to report demographic data, mental health status and COVID 19 treatment. Categorical variables were presented as counts and percentage, and continuous variables were shown in mean with $\mathrm{SD}$ or median with interquartile range (IQR) as appropriate. We used Pearson's Chi-square or Fisher's exact test to determine the difference among categorical data and student $t$-test or Mann-Whitney $\mathrm{U}$ test for continuous data. Bivariate and multivariable logistic regression were used to explore factors associated with erectile dysfunction. For multivariable model, we planned to adjust clinically important covariates including theoretically associating factor of ED together with factor with $\mathrm{P}$ value below 0.20 in bivariate model. A $\mathrm{P}$ value of $<0.05$ was considered statistically significant. STATA-IC Version 16.1 was used for analyzing data.

\section{Results}

Throughout the study period, 654 Thai men with COVID-19 were screened. We excluded 469 patients according to the criteria. Of the rest, 32 patients refused to participate, so the remaining 153 sexually active men were enrolled in our study (Figure 1). Mean age and BMI was 40.8 years and $25.6 \mathrm{~kg} / \mathrm{m}^{2}$, respectively. Most were married or couple (81.7\%), employed (93.5\%), and had educational attainment lower than bachelor's degree $(84.3 \%)$. In all participants, morning erection tended to be normal. Only $32.7 \%$ of the participants received COVID-19 vaccination, and 8 participants reported having sex with male partners. Previous use of ED medications was reported in 6 participants. There were 8 and 21 participants who screened positive for generalized anxiety disorder and major depression respectively. The overall prevalence of ED was $64.7 \%$. Mild ED (45.1\%) was the most prevalent, followed by moderate (15.7\%), and mild to moderate (3.9\%) severity. None of the participants had severe ED. Numbers of underlying diseases, past history, and substance use are shown in Table 1.

The details of COVID-19 treatment during hospitalization were shown in Table 2. Most participants were symptomatic $(92.8 \%)$ or mild symptoms and received supportive treatment $(93.5 \%)$. Corticosteroids was given to 36 participants. Meanwhile, favipiravir was prescribed seven times more than remdesivir and fourteen times more than tocilizumab. The use of each medication depended on increasing severity of COVID-19. Oxygen supplement via nasal oxygen cannula was provided for 20 participants. Regarding the severity of respiratory difficulties, 1 and 4 received an additional helmet noninvasive ventilation and high-flow nasal oxygen cannula, respectively.

Multivariable logistic regression was done (Table 3). We found a significant association between having ED and mental health status after correcting for age above forty 
Table 1 Demographic characteristics, mental health, and erectile function measurement

\begin{tabular}{|c|c|c|c|}
\hline Participants ( $N=153)$ & $\mathrm{ED}(\mathrm{N}=99)$ & Non-ED $(\mathrm{N}=54)$ & $P$ value \\
\hline Age (mean \pm SD) & $41.3 \pm 10.8$ & $39.7 \pm 11.1$ & 0.37 \\
\hline $\begin{array}{l}\text { Body mass index } \\
\text { (mean } \pm S D)\end{array}$ & $25.9 \pm 4.5$ & $25.6 \pm 4.4$ & 0.28 \\
\hline Marital status, n (\%) & & & 0.39 \\
\hline Single & $15(15.2)$ & $10(18.5)$ & \\
\hline Married or couple & $81(81.8)$ & $44(81.5)$ & \\
\hline Separated or divorced & $3(3.0)$ & $0(0.0)$ & \\
\hline Educational status, n (\%) & & & 0.35 \\
\hline $\begin{array}{l}\text { Lower than bachelor's } \\
\text { degree }\end{array}$ & $81(81.8)$ & $48(88.9)$ & \\
\hline $\begin{array}{l}\text { Bachelor's degree or } \\
\text { upper }\end{array}$ & $18(18.2)$ & $6(11.1)$ & \\
\hline Medical comorbidities & $19(19.2)$ & $10(18.5)$ & 0.92 \\
\hline Diabetes Mellitus & $9(9.1)$ & $4(7.4)$ & 0.72 \\
\hline Hypertension & $8(8.1)$ & $8(14.8)$ & 0.19 \\
\hline Hypercholesterolemia & $8(8.1)$ & $3(5.6)$ & 0.56 \\
\hline \multicolumn{4}{|l|}{ Substance use, n (\%) } \\
\hline Active alcohol drinking & $14(14.1)$ & $12(22.2)$ & 0.2 \\
\hline Active smoking & $38(38.4)$ & $19(35.2)$ & 0.7 \\
\hline \multicolumn{4}{|l|}{ Mental health status } \\
\hline $\begin{array}{l}\text { GAD-7 total score } \\
\text { [median (IQR)] }\end{array}$ & $4[1-7]$ & $2[0-3]$ & $0.004^{*}$ \\
\hline $\begin{array}{l}\text { Anxiety disorder } \\
\text { (GAD-7 } \geq 10), n(\%)\end{array}$ & $8(8.1)$ & $0(0)$ & $0.032^{*}$ \\
\hline $\begin{array}{l}\text { PHQ-9 total score } \\
\text { [median (IQR)] }\end{array}$ & $3[1-8]$ & $2[0-4]$ & $0.015^{\star}$ \\
\hline $\begin{array}{l}\text { Major depression } \\
(\mathrm{PHQ}-9 \geq 9), \mathrm{n}(\%)\end{array}$ & $20(20.2)$ & $1(1.9 \%)$ & $0.002^{*}$ \\
\hline $\begin{array}{l}\text { Normal morning erection, } \\
\mathrm{n}(\%)\end{array}$ & $84(84.8)$ & 45 (83.3) & 0.81 \\
\hline $\begin{array}{l}\text { COVID-19 vaccination, } \\
n(\%)\end{array}$ & 33 (33.3) & $17(31.5)$ & 0.82 \\
\hline
\end{tabular}

*, P value <0.05. ED, erectile dysfunction; GAD-7, Generalized Anxiety Disorder Scale; PHQ-9, Patient Health Questionnaire 9; $\mathrm{SD}$, standard deviation; IQR, interquartile range.

years which is the main age range affected by ED (10), BMI of more than $23 \mathrm{~kg} / \mathrm{m}^{2}$ which determined overweight in Asian population (11), and medical comorbidities including
Table 2 COVID-19 treatment during hospitalization

\begin{tabular}{|c|c|c|c|c|}
\hline Variables & $\begin{array}{l}\text { Total, } \\
\text { N (\%) }\end{array}$ & $\begin{array}{c}\text { ED, } \\
\mathrm{N}(\%)\end{array}$ & $\begin{array}{c}\text { Non-ED, } \\
\text { N (\%) }\end{array}$ & $P$ value \\
\hline \multicolumn{4}{|c|}{ COVID-19 diagnosis } & 0.17 \\
\hline Pneumonia & $63(41.2)$ & $44(69.8)$ & $19(31.2)$ & \\
\hline Pharyngitis & 79 (51.6) & $46(58.2)$ & $33(40.8)$ & \\
\hline Asymptomatic & $11(7.2)$ & $9(81.8)$ & 2 (18.2) & \\
\hline \multicolumn{5}{|l|}{ Medications } \\
\hline Favipiravir & $70(45.8)$ & $48(68.5)$ & $22(31.5)$ & 0.36 \\
\hline Corticosteroids & $36(23.5)$ & $24(66.7)$ & $12(33.3)$ & 0.78 \\
\hline Remdesivir & $10(6.5)$ & $9(90.0)$ & $1(10.0)$ & 0.08 \\
\hline Tocilizumab & $5(3.3)$ & $4(80.0)$ & $1(20.0)$ & 0.47 \\
\hline $\begin{array}{l}\text { Oxygen } \\
\text { supplement }\end{array}$ & $20(13.1)$ & $15(75.0)$ & $5(25.0)$ & 0.3 \\
\hline
\end{tabular}

hypertension, diabetes mellitus and hypercholesterolemia. ED was more prevalent in participants whose PHQ-9 total score indicated major depression [adjusted OR 8.45, 95\% CI: 1.01-70.96, $\mathrm{P}=0.049]$, and those with higher GAD-7 total score [adjusted OR 1.15, 95\% CI: 1.01-1.31, $\mathrm{P}=0.039$ ]. However, a statistically significant association was not seen among other variables.

\section{Discussion}

ED, the most concerning male sexual dysfunction (12), has not been widely studied in Thailand and some Asian countries. Even in this pandemic, several studies have focused on the impact of COVID-19 upon multiple dimensions of health but not on sexual function. The exact prevalence of ED among the Thai population is still lacking, both in general situations and during the COVID-19 pandemic.

The prevalence of ED among Thai patients with COVID-19 was $64.7 \%$. This was significantly higher than findings from previous studies $(13,14)$ in the normal Thai population, which estimated the prevalence around $37.5-$ $42.2 \%$ (two proportion $Z$-test $\mathrm{P}<0.05$ ). One study from Italy also reported higher prevalence of ED in COVID-19 groups compared to the normal population, after adjusting for age, BMI and psychological status (5). However, the prevalence of ED in COVID-19 patients in Thailand was significantly higher than in Italy $(64.7 \%$ vs. $28 \%, \mathrm{P}<0.05)$. 
Table 3 Bivariate and multivariable logistic regression between ED and associated factors

\begin{tabular}{|c|c|c|c|c|}
\hline Variables & \multicolumn{2}{|c|}{ Bivariate analysis } & \multicolumn{2}{|c|}{ Multivariable analysis } \\
\hline Age & $1.01[0.98,1.05]$ & 0.37 & & \\
\hline Age above 40 years & $1.57[0.81,3.07]$ & 0.18 & $2.08[0.93,4.65]$ & 0.075 \\
\hline BMI & $1.04[0.97,1.03]$ & 0.28 & & \\
\hline Married or couple & $1.02[0.43,2.41]$ & 0.96 & & \\
\hline Active smoking & $1.15[0.58,2.29]$ & 0.7 & & \\
\hline Active alcohol drinking & $0.58[0.25,1.36]$ & 0.21 & & \\
\hline Medical comorbidities (including HTN, DM, HCL) & $1.05[0.45,2.44]$ & 0.92 & $0.54[0.20,1.52]$ & 0.245 \\
\hline PHQ-9 total score & $1.15[1.04,1.28]$ & $0.01^{*}$ & & \\
\hline Major depression (PHQ-9 $\geq 9$ ) & $13.42[1.75,103.01]$ & $0.01^{*}$ & $8.45[1.01,70.96]$ & $0.049^{*}$ \\
\hline Normal morning erection & $1.12[0.45,2.76]$ & 0.81 & & \\
\hline COVID19 vaccination & $1.09[0.53,2.21]$ & 0.82 & & \\
\hline COVID19 pneumonia & $1.47[0.74,2.92]$ & 0.27 & & \\
\hline
\end{tabular}

*, P value <0.05. HTN, hypertension; DM, diabetes mellitus; HCL, hypercholesterolemia; GAD-7, Generalized Anxiety Disorder Scale; PHQ-

9, Patient Health Questionnaire 9.

We believed our differing results might be determined by both medical and psychological factors.

The differences of ACE2 receptors could genetically explain the variation in susceptibility to SARS-CoV-2 infection. The ACE2 gene polymorphism alters the number of ACE2 receptor expression, which is a binding site of the SARS-CoV-2 virus. Higher ACE2 expression is more frequent in some regions of Asia, including Thailand, and is associated with increased viral susceptibility. This genetic difference may account for the higher ED prevalence in Thailand (15).

The variants of SARS-CoV-2 are also responsible for the severity and infectivity of COVID-19 (16). Our study was done during mid-2021 which was the peak period of the B.1.1.7 variant spreading in Thailand. Well known in high transmission rate and increased severity, this strain might be dissimilar to the variant, which was not mentioned, from previous study $(17,18)$.

Our participants' mean age was older than the study in Italy, with a maximum reaching sixty-five years, and mean BMI was also higher (25.6 vs. $\left.22.5 \mathrm{~kg} / \mathrm{m}^{2}\right)$. This may be another factor, among several related bio-psychological factors that should be considered as an explanation for the difference in ED prevalence.

Interestingly, age, BMI and medical comorbidities understood to be ED risk factors were not significantly associated with ED. This could be explained by the low number of our sample size. Most participants reported having a normal morning erection, which might indicate an intact erection capacity. Thus, these biological factors might play less part in ED etiologies among our participants. Psychological impacts, including stress, anxiety, and depression, should be emphasized since they were highly correlated with ED during this pandemic, found in the prior study (19).

Mental health status was found to have remarkable influence. We used a PHQ-9 cut-off score of $\geq 9$ to classify patients as having depression, according to the validated cut-off in the Thai population. Unfortunately, the GAD-7 has never been validated in Thailand, so we used its total score instead.

Bivariate logistic regression showed significant association between ED and these two variables; PHQ-9 $\geq 9$ $(\mathrm{P}=0.01)$ and $\mathrm{GAD}-7$ total score $(\mathrm{P}=0.002)$. Multivariable 
logistic regression, adjusted for age, BMI, and medical comorbidities, also confirmed our result.

Psychogenic causes should be a primary focus for ED younger men (20). Psychological burdens, including anxiety, depression, and poor socioeconomic status, are significant risk factors of developing ED (21). During the COVID-19 pandemic, unemployment and financial crisis affected a large proportion of the Thai population, and were associated with adverse mental health outcomes $(22,23)$. Considering the current economic crisis in Thailand and its impact upon mental health, psychological issues may also contribute to the higher ED prevalence in our study population. In addition to $\mathrm{ED}$, sexual dissatisfaction was also increased during this pandemic situation (24).

Compared to patients hospitalized for non-COVID-19 conditions, the number of participants with major depression in our study was comparable; meanwhile, the prevalence of generalized anxiety disorder was lower $(25,26)$. However, the prevalence of mental problems among hospitalized patients was varied regarding each disease severity or its impact on quality of life. The study about ED prevalence during hospitalization was lacking. Many previous studies reported the number of ED in patients with stable and chronic diseases, which depended on different diagnoses (38.6-82\%) (27-31).

Compared to prior ED and COVID-19 studies, our study covered a larger sample size. All participants were confirmed with SARS-CoV-2 RT-PCR and diverse in severity and treatment. We collected important ED-related factors, including medical comorbidities, substance abuse, and mental health status.

Some limitations should be discussed in this study. It was designed in a cross-sectional method, therefore the causal relationship between ED and associated factors could not be explored. Our study population is comprised of inpatients, leading to limited generalizability to patients with mild COVID-19 who do not require hospitalization. Furthermore, investigations such as hormonal level, nocturnal penile tumescence testing, or duplex doppler ultrasound could not be conducted due to risk of COVID-19 transmission. All questionnaires could also be influenced by recall bias; thus the responders might reply mainly based on their recent periods (32). However, it was beneficial in terms of the results that could better represent the status of each individual during his acute illness of COVID-19 infection. Future prospective studies will be useful for identifying the causation of ED or its long-term effects caused by COVID-19. Also, further studies focusing the management and its accessibility are still needed to alleviate the impact of COVID-19 on men's health (33).

\section{Conclusions}

The prevalence of ED among Thai patients with COVID-19 was high. ED should be assessed as multifactorial in origin, with consideration for psychological factors. Healthcare providers are suggested to screen for mental problems in individuals with ED and vice versa, with prudent cultural consideration.

\section{Acknowledgments}

We thank Dr. Yanin Thipakorn for her grammatical reviews. Funding: None.

\section{Footnote}

Reporting Checklist: The authors have completed the STROBE reporting checklist. Available at https://dx.doi. org/10.21037/tau-21-807

Data Sharing Statement: Available at https://dx.doi. org/10.21037/tau-21-807

Peer Review File: Available at https://dx.doi.org/10.21037/ tau-21-807

Conflicts of Interest: All authors have completed the ICMJE uniform disclosure form (available at https://dx.doi. org/10.21037/tau-21-807). The authors have no conflicts of interest to declare.

Ethical Statement: The authors are accountable for all aspects of the work in ensuring that questions related to the accuracy or integrity of any part of the work are appropriately investigated and resolved. The study was conducted in accordance with the Declaration of Helsinki (as revised in 2013). The study was approved by Chulalongkorn University's Institutional Review Board (IRB No. 408/2021) and informed consent was taken from all the participants.

Open Access Statement: This is an Open Access article distributed in accordance with the Creative Commons Attribution-NonCommercial-NoDerivs 4.0 International License (CC BY-NC-ND 4.0), which permits the noncommercial replication and distribution of the article with 
the strict proviso that no changes or edits are made and the original work is properly cited (including links to both the formal publication through the relevant DOI and the license). See: https://creativecommons.org/licenses/by-nc-nd/4.0/.

\section{References}

1. Abobaker A, Raba AA, Alzwi A. Extrapulmonary and atypical clinical presentations of COVID-19. J Med Virol 2020;92:2458-64.

2. Kresch E, Achua J, Saltzman R, et al. COVID-19 Endothelial Dysfunction Can Cause Erectile Dysfunction: Histopathological, Immunohistochemical, and Ultrastructural Study of the Human Penis. World J Mens Health 2021;39:466-9.

3. Sansone A, Mollaioli D, Ciocca G, et al. Addressing male sexual and reproductive health in the wake of COVID-19 outbreak. J Endocrinol Invest 2021;44:223-31.

4. Xiong J, Lipsitz O, Nasri F, et al. Impact of COVID-19 pandemic on mental health in the general population: A systematic review. J Affect Disord 2020;277:55-64.

5. Sansone A, Mollaioli D, Ciocca G, et al. "Mask up to keep it up": Preliminary evidence of the association between erectile dysfunction and COVID-19. Andrology 2021;9:1053-9.

6. Irfan M, Hussain NHN, Noor NM, et al. Epidemiology of Male Sexual Dysfunction in Asian and European Regions: A Systematic Review. Am J Mens Health 2020;14:1557988320937200.

7. Sangkum P, Sukying C, Viseshsindh W, et al. Validation and Reliability of a Thai Version of the International Index of Erectile Dysfunction (IIEF) for Thai Population. J Med Assoc Thai 2017;100:73.

8. Lotrakul M, Sumrithe S, Saipanish R. Reliability and validity of the Thai version of the PHQ-9. BMC Psychiatry 2008;8:46.

9. Spitzer RL, Kroenke K, Williams JB, et al. A brief measure for assessing generalized anxiety disorder: the GAD-7. Arch Intern Med 2006;166:1092-7.

10. Echeverri Tirado LC, Ferrer JE, Herrera AM. Aging and Erectile Dysfunction. Sex Med Rev 2016;4:63-73.

11. WHO Expert Consultation. Appropriate body-mass index for Asian populations and its implications for policy and intervention strategies. Lancet 2004;363:157-63.

12. Eardley I. The Incidence, Prevalence, and Natural History of Erectile Dysfunction. Sex Med Rev 2013;1:3-16.

13. Kongkanand A. Prevalence of erectile dysfunction in Thailand. Thai Erectile Dysfunction Epidemiological
Study Group. Int J Androl 2000;23 Suppl 2:77-80.

14. Permpongkosol S, Kongkakand A, Ratana-Olarn K, et al. Increased prevalence of erectile dysfunction (ED): results of the second epidemiological study on sexual activity and prevalence of ED in Thai males. Aging Male 2008;11:128-33.

15. Cao Y, Li L, Feng Z, et al. Comparative genetic analysis of the novel coronavirus (2019-nCoV/SARS-CoV-2) receptor ACE2 in different populations. Cell Discov 2020;6:11.

16. Dao TL, Hoang VT, Colson P, et al. SARS-CoV-2 Infectivity and Severity of COVID-19 According to SARS-CoV-2 Variants: Current Evidence. J Clin Med 2021;10:2635.

17. Giles B, Meredith P, Robson S, et al. The SARS-CoV-2 B.1.1.7 variant and increased clinical severity-the jury is out. Lancet Infect Dis 2021;21:1213-4.

18. Ceniti AK, Heinecke N, McInerney SJ. Examining suiciderelated presentations to the emergency department. Gen Hosp Psychiatry 2020;63:152-7.

19. Bulut EC, Ertaş K, Bulut D, et al. The effect of COVID-19 epidemic on the sexual function of healthcare professionals. Andrologia 2021;53:e13971.

20. Song WH, Park J, Yoo S, et al. Changes in the Prevalence and Risk Factors of Erectile Dysfunction during a Decade: The Korean Internet Sexuality Survey (KISS), a 10-YearInterval Web-Based Survey. World J Mens Health 2019;37:199-209.

21. Rosen RC. Psychogenic erectile dysfunction. Classification and management. Urol Clin North Am 2001;28:269-78.

22. Ruengorn C, Awiphan R, Wongpakaran N, et al. Association of job loss, income loss, and financial burden with adverse mental health outcomes during coronavirus disease 2019 pandemic in Thailand: A nationwide crosssectional study. Depress Anxiety 2021;38:648-60.

23. Mongkhon P, Ruengorn C, Awiphan R, et al. Exposure to COVID-19-Related Information and its Association With Mental Health Problems in Thailand: Nationwide, Cross-sectional Survey Study. J Med Internet Res 2021;23:e25363.

24. Li W, Li G, Xin C, et al. Challenges in the Practice of Sexual Medicine in the Time of COVID-19 in China. J Sex Med 2020;17:1225-8.

25. Kayhan F, Cicek E, Uguz F, et al. Mood and anxiety disorders among inpatients of a university hospital in Turkey. Gen Hosp Psychiatry 2013;35:417-22.

26. Huang M, Liu Y, Wang J, et al. High rates of depression anxiety and suicidal ideation among inpatients in general hospital in China. Int J Psychiatry Clin Pract 
2019;23:99-105.

27. Yang M, Sun HL, Jackson SC. Erectile dysfunction in patients with haemophilia. Haemophilia 2019;25:283-8.

28. Maimone S, Saffioti F, Oliva G, et al. Erectile dysfunction in compensated liver cirrhosis. Dig Liver Dis 2019;51:843-9.

29. Platek AE, Hrynkiewicz-Szymanska A, Kotkowski M, et al. Prevalence of Erectile Dysfunction in Atrial Fibrillation Patients: A Cross-Sectional, Epidemiological Study. Pacing Clin Electrophysiol 2016;39:28-35.

30. Kouidrat Y, Pizzol D, Cosco T, et al. High prevalence of erectile dysfunction in diabetes: a systematic review and meta-analysis of 145 studies. Diabet Med 2017;34:1185-92.

Cite this article as: Harirugsakul $\mathrm{K}$, Wainipitapong $\mathrm{S}$, Phannajit J, Paitoonpong L, Tantiwongse K. Erectile dysfunction among Thai patients with COVID-19 infection. Transl Androl Urol 2021;10(12):4376-4383. doi: 10.21037/tau21-807
31. Pyrgidis N, Mykoniatis I, Nigdelis MP, et al. Prevalence of Erectile Dysfunction in Patients With End-Stage Renal Disease: A Systematic Review and Meta-Analysis. J Sex Med 2021;18:113-20.

32. Rosen RC, Cappelleri JC. The sexual health inventory for men (IIEF-5): reply to Vroege. Int J Impot Res 2000;12:342-3.

33. Hsieh TC, Edwards NC, Bhattacharyya SK, et al. The Epidemic of COVID-19-Related Erectile Dysfunction: A Scoping Review and Health Care Perspective. Sex Med Rev. 2021. [Epub ahead of print]. doi: 10.1016/ j.sxmr.2021.09.002. 